\title{
Gammu and kalkun for information services and sales based on information technology
}

\author{
Joseph Teguh Santoso ${ }^{1}$, Mars Caroline Wibowo ${ }^{2}$, Budi Raharjo ${ }^{3}$, Mufadhol Mufadhol ${ }^{4}$ \\ ${ }^{1,4}$ Department of Computer System, STEKOM University Semarang, Indonesia \\ ${ }^{2,3}$ Department of Computer Graphics, STEKOM University Semarang, Indonesia
}

\begin{tabular}{l} 
Article Info \\
\hline Article history: \\
Received May 24, 2019 \\
Revised Oct 31, 2019 \\
Accepted Nov 15, 2019 \\
\hline
\end{tabular}

Keywords:

Gammu

Kalkun

Information service

Sales

Information technology

\begin{abstract}
The rapid development of information technology forces everything to be done sophisticated, easy, and practical. During the information technology revolution 4.0 which is commonly called the disruptive era, the people need communication to exchange information and data. One of the communication systems that has been found today is handphone technology that can be used to communicate remotely through short message services. It can be ascertained that almost every adult having a handphone can be even more than one number, so it is a top priority for market sharing in business activities by utilizing gammu and kalkun technology. Gammu which is an open source program application was developed to build SMS gateways and or while the kalkun program application is used for web based SMS management system. This paper describes the use of gammu and kalkun in information technology to develop and manufacture and manage SMS SERVER effectively and certainly can save costs. This method is more efficient because it allows companies to easily manage their own information dissemination and sales activities and according transactions to business needs, so that the budget spent by the company can be reduced and more economical.
\end{abstract}

Copyright $@ 2020$ Institute of Advanced Engineering and Science. All rights reserved.

\section{Corresponding Author:}

Mufadhol Mufadhol,

Department of Computer System,

STEKOM University Semarang,

Jl. Majapahit 605, Pedurungan, Semarang, Indonesia.

Phone $+62246723456,+62246710144$.

Email: masyong29@gmail.com

\section{INTRODUCTION}

Information services and sales with base on information technology is one of the driving factors in the business. The information is presented through a short message is very effective and can be saving of marketing costs with the main goal of increasing sales [1]. Indonesia has a population growth of $3.5 \%$ of the world's population growth, making it the fourth place in the world population and almost everyone has a celluler phone, even the tendency to have more than one number either from the same provider number or provider or from another provider [2]. The communication is done to exchange or search for information wherever and whenever, one of the communication systems that have been used is short message technology through mobile phones that can be tailored to the needs and able to be used for remote communication [3].

Short message services are currently widely used by companies in business for information dissemination or transaction activities [4]. Short message costs are relatively inexpensive and are privacy, when using short message technology users can be kept secret if they are in a crowd because those who know and can read messages are only users themselves [5]. A short message can be developed to build SMS SERVER by utilizing gammu and kalkun technology [6]. Via SMS SERVER companies can manage themselves through the admin according to the needs of the business and the admin can also send messages 
to the destination quickly and precisely [7], as seen in Figure 1. Gammu technology in information technology is used as a means to create an SMS gateway that can direct short messages to customers directly. Kalkun technology is used to manage web-based short messages [6-8]. Combination use of the gammu application programs and kalkun technology can be used to deliver product information in the form of goods and services to customers directly via a short message. This kind of marketing model can save costs and can even be called effective and efficient, so that consumers can feel well served because getting up-to-date information services from companies with the ultimate goal is sales can increase.

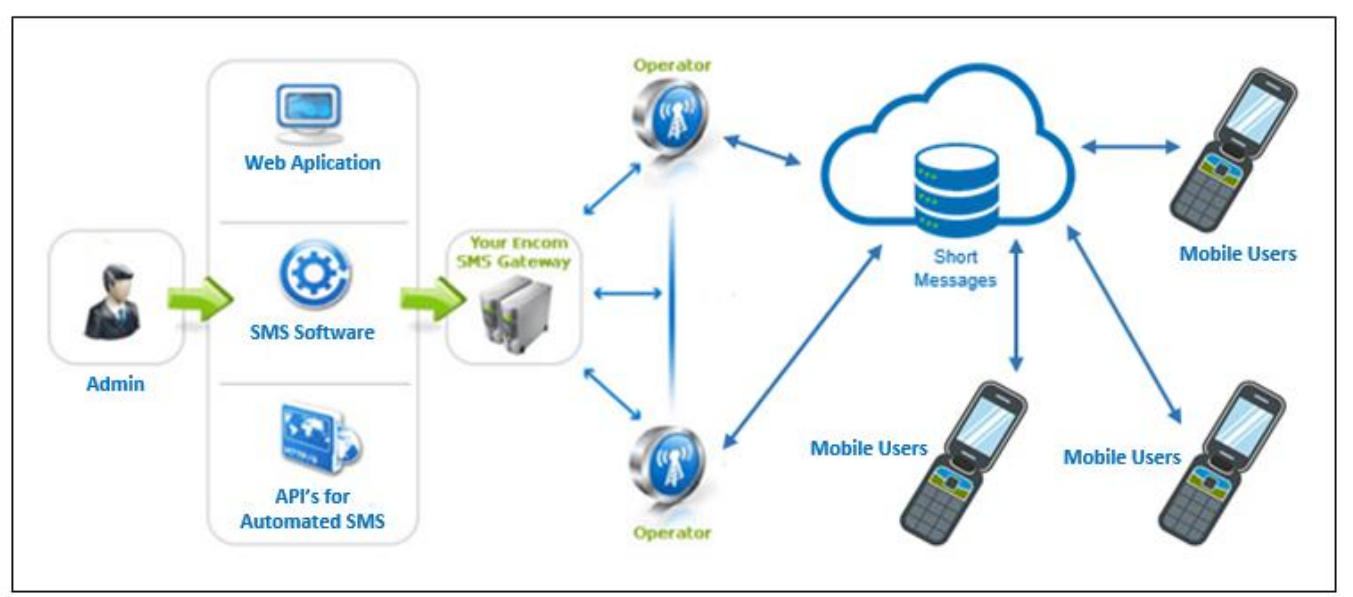

Figure 1. SMS gateway and server

\section{RESEARCH METHOD}

In order for research to run in detail and thoroughly, in the development of research with gammu and kalkun technology it will be carried out using the research and development method [9]. This method allows directly involving users in this case businessmen or entrepreneurs in the research conducted, so that the company's needs for the system can be fulfilled.

\subsection{SMS server and SMS gateway}

SMS servers are designed to regulate the exchange of information with customers via short messages and used in information technology created for transaction activities as well as for information services and sales. Distribution of information from SMS servers, questions, suggestions, and requests from business customers can be managed properly. As seen in Figure 2. SMS gateway is an application system that is used to send also receive SMS, and is usually used in business applications, both for broadcast promotion purposes (Bulk SMS), information services to users, dissemination of product content and services, etc [7, 10]. SMSD (SMS daemon) is a program module for receiving and sending SMS that works by using SQL server to store all inboxes and outboxes in the cellular SMS daemon that can support two database modules namely MySQL and PostgreSQL [11].

\subsection{Gammu application program}

Gammu is an open source application service and contains several command line utilities and is used to control phone functions and in general in the form of mobile phones and modems [6, 12]. Gammu is written using the $\mathrm{C}$ programming language and developed using the libGammu library. Gammu can run various accesses to various phone features, one of which is the SMS Gateway application [8, 13]. As seen in Figure 3.

\subsection{Kalkun technology}

The kalkun is a web based short message management that is an open source. Kalkun is released under the GNU General Public License, the program code for kalkun is free to change and redistribute source code that has changed. Kalkun uses gammu-smsd as a SMS Gateway engine to deliver and retrieve messages from a telephone or modem. Kalkun and gammu is two different things. Kalkun is only manages the database provided by Gammu $[6,14]$. Kalkun's architecture can be seen in Figure 4. Kalkun's web based and only need to put this software on one computer as a server. 


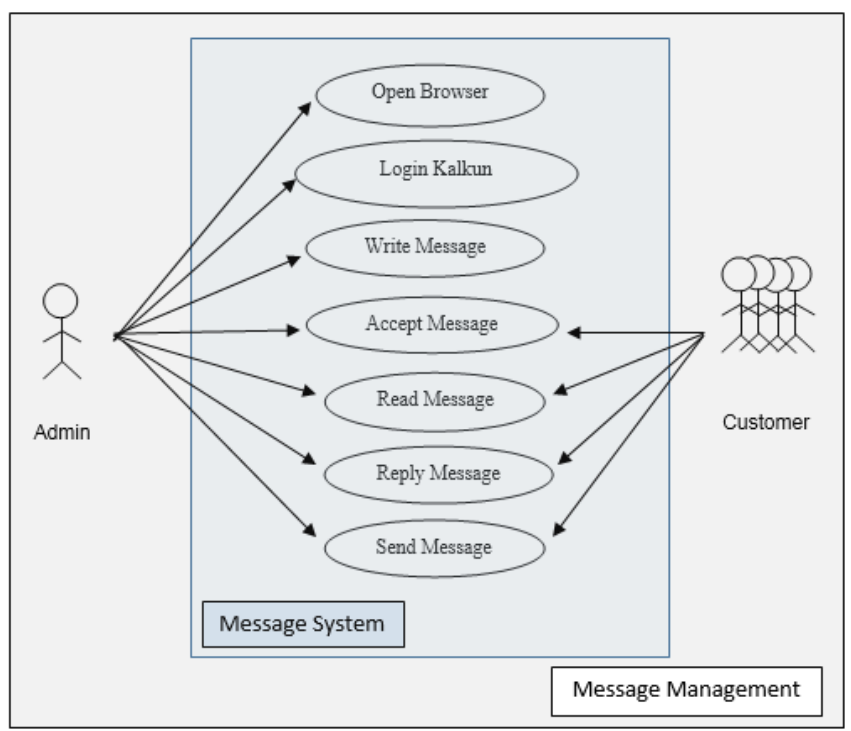

Figure 2. Message management system

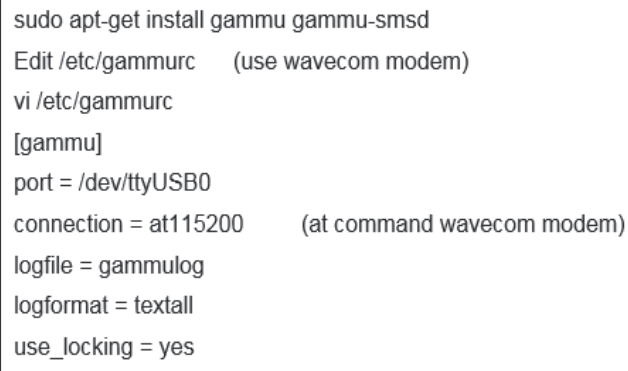

Figure 3. Gammu command line utility

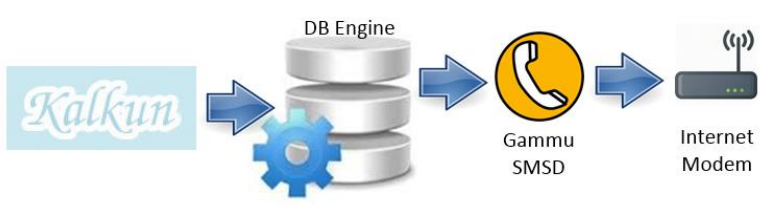

Figure 4. Kalkun's Architecture

\section{RESULTS AND ANALYSIS}

\subsection{Information services and sales}

Information services and sales are facilities or services regarding specifications or information about goods or services that will be offered and provided by the company for prospective customers so that the goods or services can attract consumer interest [1,3,15]. Each customer has a level of demand for different products, so we need a service that can provide information more quickly and accurately and make customers feel satisfied. Submission of information can be done through communication, either face to face or even direct communication conducted through other media, such as phone, chat or even via SMS $[4,16]$.

\subsection{Gammu server installations}

Gammu server is a cross-platform application that is used to bridge and communicate between SMS Gateway databases with SMS devices, as shown in Figure 5. The first step in installing gammu server on a Linux operating system is to make sure the modem is available and ready to use on the internet [6, 17]. 
Applications in Gammu can be daemons that run in the background. Gammu will move the incoming SMS to SMS devices, thus gammu will immediately move it into the inbox in the SMS gateway database. Conversely when the SMS Sending Application enters an SMS into outbox in the SMS gateway database, then your gammu will send it back via SMS devices, and move the SMS to the sentitem in the database.

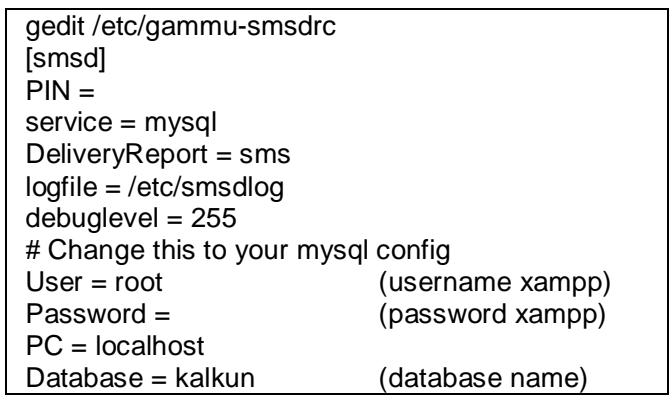

Figure 5. Connection database and device SMS

\subsection{Kalkun database settings}

The kalkun is a device for the management of SMS, so that it can be used properly, before installation please make sure the kalkun is already installed Gammu [6-8, 18]. Kalkun must be installed on the Linux operating system by extracting the software first, then entering the directory and then creating and managing the database, as shown in Figure 6, after which the kalkun application can be used.

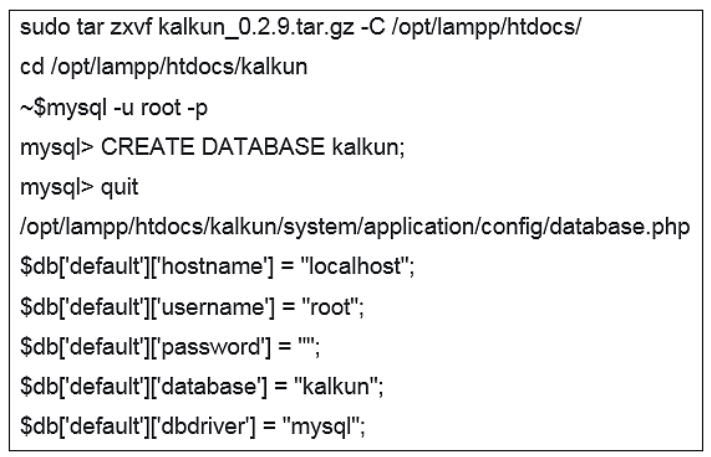

Figure 6. Create and setting database

\subsection{SMS mangement system}

The need to create as well manage the SMS Gateway is very simple and flexible [19], this system can be used simply by using a Personal Computer or Notebook, modem and data cable, of course with regard to the design of the computer network used [20]. The operating system used is Linux with a database server in the form of lampp, while the technology for managing celluler phones and modems is Gammu and for short message management via the web using kalkun. To run this system first to make sure the modem is plugged in and recognized by the Linux operating system as the Figure 7, modems have an important role and function to connect between application systems with global networks or the internet. After the modem is connected, then make sure the Gammu application program is also running on the Linux operating system and there are no error messages, so that the Gammu application program runs optimally as a means of connecting program between the SMS device with the SMS gateway that runs hidden or often called runs in the background, as shown in Figure 8. Then after everything is running smoothly and in accordance with their respective functions and not found errors both hardware and software, the system is ready to use, as shown in Figure 9. 


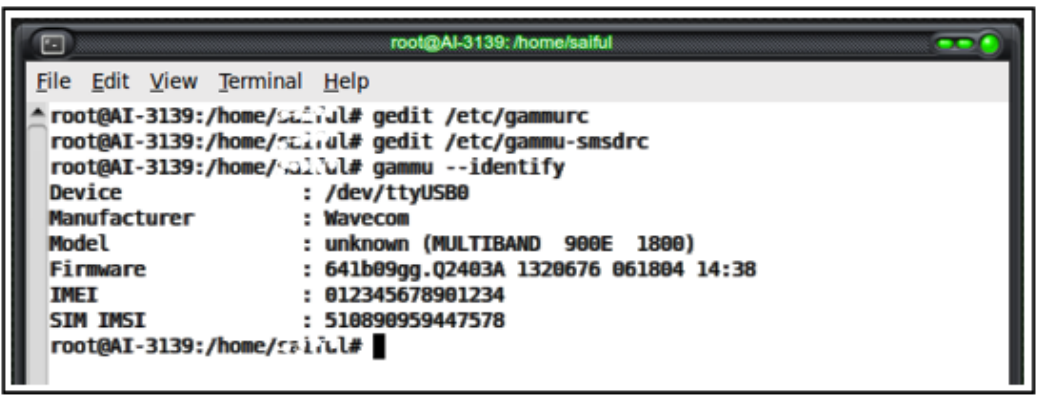

Figure 7. Modem installed

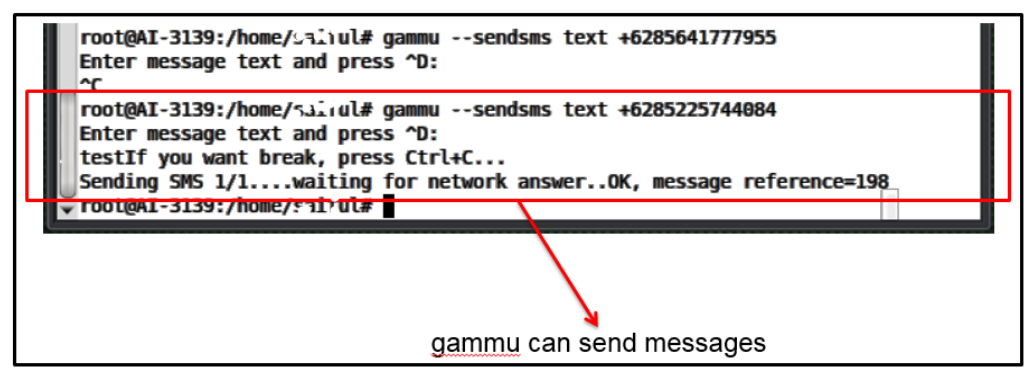

Figure 8. Gammu on linux operating system

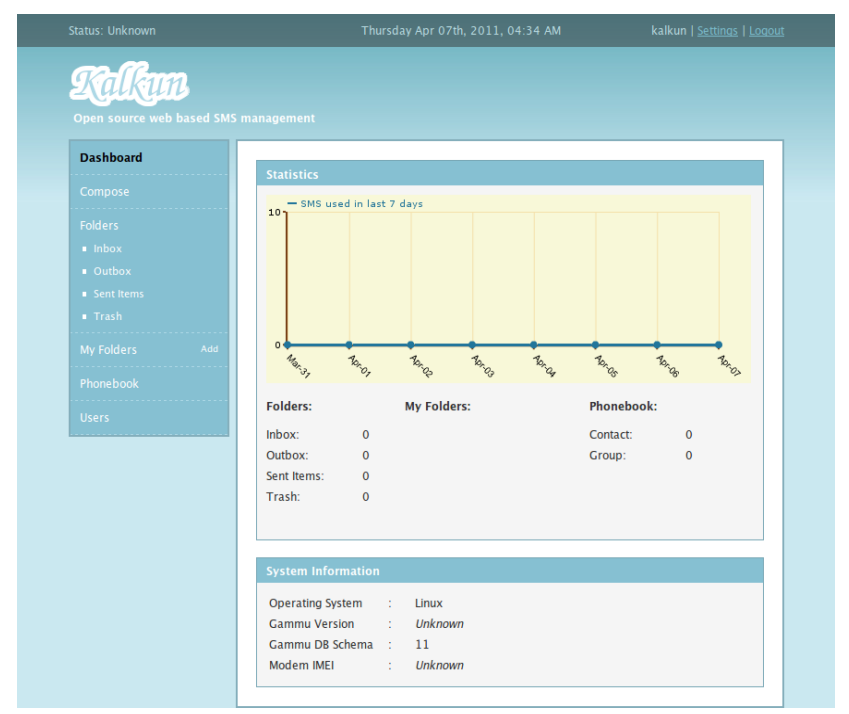

Figure 9. SMS aplication system

\subsection{Transaction increases}

Indicators of success in the function and benefit or main goal in the research can be measured after using this application program [21]. The company can send short message to customers in the form of information services about products that can be in the form of goods or services, so that transactions increase. This increase occurred in customers who asked about products and services via telephone by five percent, while for customers who came directly to companies through stores increased by seven percent. The increase in customers who come to companies is greater because customers want to get direct, detailed information and can see or witness the benefits and promotions offered by the company. The total number of purchase transactions made by customers only increased by two percent, this is because not all customers who ask by telephone or who come directly make a purchase transaction. 


\section{RECOMMENDATIONS}

This system still requires an administrator to deliver sales information, in the future it is expected that the system can be developed with the auto reply method so that this application can also automatically send information or answer questions from the consumer. Can be developed using rules in the rule based reasoning method [22], fuzzy logic model [23] or expert system solution [24], managed online with a simple routing system [25], and stored in the cloud database system [26].

\section{CONCLUSION}

The combination using gammu and kalkun on this system can be used to read and send short messages via a computer by connecting a cellphone and modem under the control of a Linux operating system. This application does not depend on one brand mobile phone or modem, but can be used for various other brands that can support device connection to the internet. This method allows an administrator to manage messages as well as a means to deliver information and sales to consumers, become easier, faster and on target and can reduce budgetary expenditure for marketing costs with the main goal of getting a lot of profits by increasing sales.

\section{ACKNOWLEDGEMENTS}

This research is supported by Departement of Computer System, STEKOM University Semarang under the supervision of Research institutions and community service of STEKOM University Semarang, Indonesia, and also this research is the result of collaboration with Mastery On Going Company Semarang, Indonesia.

\section{REFERENCES}

[1] M. Wu, R.H. Teunter and S.X. Zhu, "Online marketing: When to offer a refund for advanced sales," International Journal of Research in Marketing, vol. 36(1), pp. 1-21, 2019.

[2] A. Wibowo, G. Aryotejo and M. Mufadhol, "Accelerated Mobile Pages from JavaScript as Accelerator Tool for Web Service on E-Commerce in The E-Business," International Journal of Electrical and Computer Engineering, vol. 8(4), pp. 2399-2405, 2018.

[3] K. Sarikakis, I. Korbiel and W.P. Mantovaneli, "Social control and the institutionalization of human rights as an ethical framework for media and ICT corporations," Journal Of Information, Communication And Ethics In Society, vol. 16(3), pp. 275-289, 2018.

[4] F. Bamba and S.J. Barnes, "SMS advertising, permission and the consumer: a study," Business Process Management Journal, vol. 13(6), pp. 815 - 829, 2007.

[5] K. Yang, K. Zhang, J. Ren and X.S. Shen, "Security and Privacy in Mobile Crowdsourcing Networks: Challenges and Opportunities," IEEE Communications Magazine, vol. 53(8), pp.75-81, 2015.

[6] T. Susilowati, M.I. Dacholfany, S. Aminin, A. Ikhwan, B.M. Nasir, M. Huda, A. Prasetyo, A. Maseleno, F. Satria, S. Hartati and W. Wulandari, "Getting parents involved in child's school: using attendance application system based on SMS gateway, ” International Journal of Engineering \& Technology, vol. 7(2), pp. 167-174, 2018.

[7] B.I. Ahmad, F. Yakubu, M.A. Bagiwa and U.I. Abdullahi, "Remote Home Management: An alternative for working at home while away," World of Computer Science and Information Technology Journal, vol. 1(4), pp. 144-147, 2011.

[8] F. Sari and P. Lidya, "Mobile Application Reminder of SPP Payment Schedule's and School Activities Information Based SMS Gateway," Journal of Telecommunication, Electronic and Computer Engineering, Vol. 9(3-8), pp. 27-31, 2017.

[9] M. Mufadhol, S. Siswanto, D.D. Susatyono and M.U. Dewi, "The Phenomenon of Research and Development Method in Research of Software Engeneering," International Journal of Artificial Intelligece Researh, Vol. 1(1), pp. 1-5, 2017.

[10] V.K. Katankar and V.M. Thakare, "Short Message Service using SMS Gateway," International Journal on Computer Science and Engineering, vol. 2(4), pp. 1487-1491, 2010.

[11] M.D. Leom, K.R.Choo and R. Hunt, "Remote Wiping and Secure Deletion on Mobile Devices: A Review," Journal of Forensic Sciences, vol. 61(6), pp. 1473-1492, 2016.

[12] S. Ismail and M.N. Husen, "Adoption of SMS and Web Based System to Measure Usability and Effectiveness of Text Alert System as Broadcast Communication for Managing and Disseminating Information," International Journal of Computer and Communication Engineering, Vol. 2, No. 1, pp. 33-35, 2013.

[13] A. Huck, J. Utke and C. Bischof, "Source Transformation of C++ Codes for Compatibility with Operator Overloading," Procedia Computer Science, vol. 80, pp. 1485-1496, 2016.

[14] S.M. Abdulhamid, M.S.A. Latiff, H. Chiroma, O. osho, G.A. Salaam, A.I. Abubakar and T. Herawan, "A Review on Mobile SMS Spam Filtering Techniques," IEEE Access, vol. 5, pp. 15650- 15666, 2017.

[15] J. Bernicot, O.V. Legrier, A. Goumi and A.B. Erboul, "Forms and functions of SMS messages: A study of variations in a corpus written by adolescents," Journal of Pragmatics, vol. 44, pp. 1701 - 1715, 2012. 
[16] A. Persaud and I. Azhar, "Innovative mobile marketing via smartphones: Are consumers ready?," Marketing Intelligence \& Planning, vol. 30(4), pp. 418-443, 2012.

[17] K.C. Chan and D. Tien, "A Multi-tenant Platform for SMS Integrated Services," International Journal of Computer Networks \& Communications, vol. 5(6), pp. 205-214, 2013.

[18] J.J. Siregar and R. Rubil, "The Prototype Design Academic Information for Management of Exams Quiz University Students based on SMS Gatewaym," Journal of theoretical and applied information technology, vol. 65(1), pp. 248-253, 2014.

[19] N.S.N.A. Aziz, N.F.M. Sani, R. Othman and H. Othman, "The Implementation of Finite State Automata in Government SMS Services (MySMS)," Australian Journal of Basic and Applied Sciences, vol. 9(31), pp. 47-52, 2015.

[20] M. Mufadhol, G. Aryotejo and D.E. Kurniawan, “The Network Planning Concept for Increase Quality of Service using Packet Tracer," The 2nd International Conference on Applied Engineering (ICAE), Batam, Indonesia, October 2019.

[21] U. Achlison and M. Mufadhol, "Research Management in Virtual Organization between Higher Education and Industry for Developing Lecture's Knowledge," Journal of KINETIK, vol. 4(1), pp. 1-12, 2019.

[22] M. Mufadhol, G. Aryotejo and D.Y. Kristiyanto, "Rule Based Reasoning Method for Safety Room by Means of Temperature Sensor and Motion Detector," International Journal of Advanced Science Letters, Vol. 23(3), pp. 2481-2483, 2017.

[23] M. Mufadhol, S. Siswanto and M.U. Dewi, "Fuzzy Logic for Automatically Performance Assessment using CIOWA Model," Journal of Telematics and Informatics, vol. 6(4), pp. 244-252, 2018.

[24] S. Maharani, S.I. Persyadha, D. Cahyadi and M. Mufadhol, "Weighted Product Method for Selection of Superior Seeds Catfish in The Clarias Gariepinus Types (Sangkuriang)," The 4th International Conference on Energy, Environment, Epidemilogy and Information System (ICENIS), Semarang, Indonesia, August 2019.

[25] M. Mufadhol, G. Aryotejo and A. Wibowo, "Netscan and Networx for Management Bandwidth and Traffic with Simple Routing," TELKOMNIKA Telecommunication, Computing, Electronics and Control, Vol. 15(1), pp. 464-470, 2017.

[26] G. Aryotejo, D.Y. Kristiyanto and M. Mufadhol, "Hybrid cloud: bridging of private and public cloud computing", Journal of Physics: Conference Series, vol. 1025(012091), pp. 1-7, 2018. 